\title{
SURINAAMS NEDERLANDSE PLANTE- EN DIERENAMEN EN HUN HERKOMST
}

Men spreekt in Suriname anders Nederlands dan in Nederland. Dat geldt voor alle aspecten van de taal, zoals de woordenschat, de grammatica, de syntaxis en de uitspraak. Of gesproken kan worden van een Surinaams dialect blijft hier buiten beschouwing, we stellen slechts vast dat er een Surinaams Nederlands bestaat.

In dit artikel wordt een overzicht gegeven van dieren en planten die in het Surinaams Nederlands (SN) en het Algemeen Beschaafd Nederlands $(A B N)$ verschillend worden aangeduid èn dieren en planten die in het $\mathrm{SN}$ met een woord worden aangeduid dat ook in het $\mathrm{ABN}$ voorkomt maar daar iets anders betekent, terwijl ze in het ABN geen naam hebben. Dit betekent dus o.m. dat een dierenaam als katoenvogeltje en een plantenaam als maripa niet worden genoemd: het betreft organismen voor welke geen ABN naam bestaat, terwijl deze woorden op zich in het ABN geen betekenis hebben. Daarentegen zijn wel opgenomen namen als zoutje (soort kwal) en waterkanon (soort plant), omdat die woorden wel in het $\mathrm{ABN}$ voorkomen, maar met een andere betekenis, terwijl het $\mathrm{ABN}$ voor deze organismen geen eigen woord heeft.

Wat hun herkomst aangaat: veel SN namen zijn leenwoorden uit andere talen, al of niet vernederlandst. Onder deze is de grootste groep afkomstig uit Surinames eigen creolentaal, die de lingua franca van het land geworden is. Deze taal, die vroeger bekend stond als taki-taki of Neger-Engels, wordt tegenwoordig Sranan-tongo genoemd, of kortweg Sranan (S).

Vele Sranan woorden gaan terug op het Engels (E) en het is bij een aantal vernederlandste woorden moeilijk uit te maken of ze rechtstreeks uit het Engels dan wel via het Sranan in het SN terecht gekomen zijn.

$\mathrm{Na}$ die van het Sranan en het Engels is de rol van het Karaïbisch $(\mathrm{K})$ het grootst.

De hieronder onderscheiden categorieën sluiten elkaar op grond van hun omschrijving niet geheel uit. Een categorie moet dan ook steeds opgevat worden als bestaande uit de woorden die aan de omschrijving voldoen, voor zover ze niet ook al aan de omschrijving van een eerder genoemde categorie voldeden en daar genoemd werden. 
Ook deze rangschikking blijft een schematisering, die geen recht doet aan allerlei ingewikkelder gevallen die juist tot de interessantste behoren. Zie bijvoorbeeld wat hierboven gezegd is over de relatie tussen het Sranan en het Engels. Aan zo'n geval, ondergebracht bij de categorie in welke het het best lijkt te passen, wordt een extra woordje gewijd, ò het is opgenomen in de restgroep achteraan.

De schriifwijze van het Sranan volgt de Woordenlijst van het Sranan-tongo (1961), die van het Nederlands de Woordenlijst van de Nederlandse taal (1954).

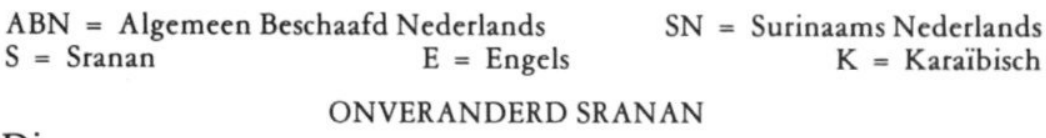

ONVERANDERD SRANAN

Dieren

Het doodskopaapje wordt monkimonki genoemd, de kapucijnapen keskesi. De naam van het rolstaartbeertje is net'keskesi, wat ongeveer nachtaapje betekent. De twee ottersoorten (een Pteronura- en een Lutra-soort) noemt men watra-dagoe, d.i. waterhond, een naam die wel afkomstig zal zijn van het oud-Engelse water-dog. Het wasbeertje (een andere soort dan de bekende Noordamerikaanse) heet krab'dagoe, d.i. krabbenhond.

Bekende vogels uit het bos zijn de kamikami (van K agami), de trompetvogel, en de anamoe's, bospatrijzen, die in Nederlandse dierentuinen als tinamou of tinamoe worden angeduid. Ik vermoed, dat al deze woorden teruggaan op hetzelfde Indiaanse woord. Onvervalst Sranan is weer ting'fowroe-granman voor koningsgier, wat betekent: opperhoofd van de stinkvogels (zie stinkvogel).

Iedere Nederlander zal de Surinaamse Alcidinidae ijsvogels noemen; de Surinamer noemt ze fis'man, d.i. visser. Evenzo zijn de Surinaamse vertegenwoordigers van het geslacht Caprimulgus, die men boetaboeta noemt (evenals nog enige verwante soorten), net als de Nederlandse: nachtzwaluwen.

De king (een klanknabootsing) is de zwarte tanager, terwijl we in het ABN alle soorten aka roofvogels noemen. Aka kan ontleend zijn aan het Engelse hawk, maar ook moet bedacht worden dat het in het Sranan tevens haak en hebzucht betekent.

Slangen: aboma (afkomstig van een Westafrikaans woord) is anakonda, makaslang of maka (= doorn) is bushmaster en swipi zweepslang. 
De soepschildpad heet krapé. Van de lederschildpad worden op grond van de vorm van de rugschildjes twee vormen onderscheiden: de aitkanti ('achtkant') en de siksikanti ('zeskant'). De harder (of aarder, een vis) is kweriman ('kliever'), een fjofjo is een wants, i.h.b. een bedwants of wandluis, en een sika een zandvlo.

\section{Planten}

Enige waterplanten: doksi-wiwiri ('eendeblad') is kroos (enige soorten Lemnaceae), pankoekoe-wiwiri ('pannekoekblad') is waterlelie (enige soorten Nymphaea) en watramama-bobi (borst van de watramama, een watergeest) is waterhyacint.

Enige vruchten: manja(boom) is mango, markoesa is (de vrucht van) enige soorten passiebloem.

Verder: injisopo ('Indianezeep') is mauritiushennep, mangro is mangrove en alle boomwurgers heten abrasa (a brasa $=$ hij omarmt).

\section{VERNEDERLANDST SRANAN}

NB. : De k in het achtervoegsel $k i$ in het Sranan heeft een klank die ligt tussen k en tj. De uitspraak van $k i$ komt tje dus zeer nabij.

\section{Dieren}

Sagoewintje (S sagoewenki) is roodhand-zijdeaapje. Onions (1967) voert het Engelse sagoin via het Frans en het Portugees terug op sagui, dat in het Guarani, een Indianentaal uit Brazilië, de naam is van een aantal kleine apesoorten.

De dwergmiereneter wordt likan genoemd, van het Sranan lek'anoe $(l e k i=$ likken, anoe $=$ hand $)$.

Anaatje (S anaki) is een soort taling (Anas bahamensis), doks ( $\mathrm{S}$ dokst) is eend in het algemeen, waaronder bosdoks (S boesidokst) de muskuseend.

Powies (S powisi, wat ook veel in het SN gebruikt wordt) is de gekuifde hokko. NB: De Karaibische naam voor deze vogel is woko. De kolibries heten kortje (S korkz).

Een geheel Nederlandse klank treffen we aan bij: blauwtje (of blauwfoortje, S blawki of blawforki) voor blauwe tanager, timmerman (S temreman) voor specht en stinkvogel (S ting'fowroe) voor zwarte aasgier. In het laatste geval betwijfel ik of het Sranan woord bestond voór het SN woord. Dat geldt ook bij Spaanse vrouw (of Spaanse dame, S spansfrow), dat bidsprinkhaan betekent. 
Planten

Ten aanzien van alle hieronder te noemen gevallen doet zich dezelfde vraag voor als hierboven bij stinkvogel en Spaanse vrouw: is het SN woord ontstaan uit het Sranan woord? We kunnen slechts vaststellen dat beide woorden bestaan, voor het moment weten we niets over de historie van hun relatie.

Drie marktprodukten: kousebandje (S kowsbanti) is een snijboon die een cultuurvorm is van Vigna sinensis (Papilionaceae), soepgroente ( $\mathrm{S}$ soepoe-wiwir) is iets anders dan in het $\mathrm{ABN}, \mathrm{nl}$. selderie, en vleesgroente ( $\mathrm{S}$ meti-wiwirt) is peterselie.

Waterkanon (S watra-kanoe) is het geneeskruid Ruellia tubiflora (Acanthaceae).

Er zijn twee siergewassen: de matrozenroos (S matrosi-rowsoe), in het ABN hibiscus of Chinese roos (Hibiscus rosa-sinensis, Malvaceae) geheten, en de vieruursbloem (S fojoeroe-bromki), de nachtschone. Het is ook denkbaar, dat de laatste twee woorden beide vertalingen zijn van het Engelse four o'clock flower.

\section{KARAÏBISCHE WOORDEN, OVERGENOMEN IN EN EVENTUEEL AANGEPAST AAN HET SRANAN}

Het Sranan heeft een aantal dierenamen overgenomen van de Karaïben, de grootste Indianenstam van Noord-Suriname. Uiteraard worden hier, evenals bij de vorige categorieën, alleen de dieren genoemd die ook in het ABN een (andere) naam hebben.

Zuiver Karä̈bisch bleven: kwata (zwarte slingeraap), pakira (halsband-pekari), aira (taira; deze naam komt duidelijk van hetzelfde Indiaanse woord; de combinatie doet denken aan anamoe en tinamoe: zie aldaar), awari (opossum, buidelrat), kapasi (gordeldier), koejakè (toekan), sipari (ev. S. spari, pijlstaartrog) en koepari (teek).

Een kleine verandering ondergingen: kapoewa (K kapiwa, waterzwijn), kwaskwasi (K kwasikwasi of kwasi, neusbeer) en pingo (K poindo of poeingo, pekari).

Vele soorten reiger heten in het Sranan sabakoe, terwijl het Karaïbisch sawakoe alleen betrekking heeft op de kleine soorten. 
NAMEN DIE IN HET ABN AAN EEN ANDER DIER OF EEN ANDERE PLANT GEGEVEN WORDEN

Deze grote groep, die vooral onder de plantenamen rijk vertegenwoordigd is, is zeer interessant. Zowel bij de dieren als bij de planten kunnen nog weer twee ondergroepen onderscheiden worden, nl. één van namen behorende bij organismen die ook in het $A B N$ een naam hebben en één waarbij dat niet zo is.

Vele namen corresponderen met een Sranan naam die erop lijkt, maar het lijkt steeds aannemelijk dat de SN naam niet uit de Sranan naam is voortgekomen.

\section{Dieren met een $\mathrm{ABN}$ naam}

De buffel (S bofroe) is de (Amerikaanse) tapir, de tijger (S tigrt) de jaguar en de poema, de vos de savannehond en de haas (S e ) de pakka.

Opmerkelijk is de naam konïn voor de goudhaas of agouti. Dit dier heet in het Sranan konikoni. Dit lijkt afkomstig te zijn van het oud-Engelse cony of coney, dat in de betekenis van konijn alleen nog voorkomt in verordeningen en in de heraldiek, en in de betekenis van konijnebont nog dialectisch wordt aangetroffen.

Men noemt in Suriname een koe graag een rund, hoewel men het eerste woord wel kent.

Enige vogels: goudvink (goudtanager), raaf (S lafroe, ara), duikelaar (slangehalsvogel en een soort aalscholver), zeegans (S segansi, flamingo), flamingo (rode ibis), krombek (regenwulp) en dikkop (S deki-ede, geelkruinkwak).

Wurm (S woron) betekent zowel worm als rups, net als het Engelse worm.

\section{Dieren zonder een $\mathrm{ABN}$ naam}

Enige zangvogels: kanarie (S kanari, enige soorten Euphonia en andere zangvogeltjes), kardinaal (Pipra aureola), putter (Molothrus bonariensis minimus), roodborstje (Leistes militaris), spotvogel (of spotlijster, Mimus gilvus, de Amerikaanse mocking bird).

Andere vogels: kemphaantje (S kepanki, de ralachtige Jacana spinosa), zeeduif (S sedoifi, de meeuw Larus atricilla). Vele grote 
en kleine waadvogels, waaronder ook enige snippen, worden snip (S snepi) genoemd. De naam papegaai (S popokai) heeft alleen betrekking op de soorten van middelmatige grootte; de grotere noemt men raaf, de kleinere parkiet.

Andere dieren: baars (allerlei witvisjes die in het Sranan sriba heten), sardientje of sardijntje (Pellonia flavipinnis, een visje van riviermonden), kameleon (de boomhagedis Polychrys marmoratus, in het Sranan agama).

\section{Planten met een $\mathrm{ABN}$ naam}

Citrus: (vrucht van) citrussoorten, i.h.b. sinaasappel(boom). In feite is Citrus de wetenschappelijke naam van het geslacht waartoe al deze planten behoren. Deze is echter gemeengoed geworden.

Kastanje(boom): (vrucht van) een vorm van de broodvruchtboom (niet de vorm die ook man-van-woord wordt genoemd).

Snijboon: boon die een Nederlander op grond van de vorm een spercieboon zou noemen; hij moet echter gesneden worden. De Surinaamse snijboon en de Nederlandse snij- en spercieboon zijn alle cultuurvormen van Phaseolus vulgaris (Papilionaceae).

Peper is Spaanse peper, reseda is henna en riet is suikerriet.

\section{Planten zonder een ABN naam}

Siergewassen: boterbloem: Gloxinia perennis (Gesneriaceae); krokus (vernederlandsing van de wetenschappelijke geslachtsnaam Crocus): een soort Zephyranthus (Amaryllidaceae); madeliefje: Gynandropsis speciosa (Capparidaceae); viooltje: een soort Torenia (Scrophulariaceae); vergeetmijnietje: Evolvulus filipes (Convolvulaceae); winde: Ipomoea carnea (Convolvulaceae, een niet-windende struik); gouden regen: Cassia fistulosa (Caesalpiniaceae); jasmijn: Tabernaemontana coronaria (Apocynaceae); kattestaart: Acalypha macrostachya (Euphorbiaceae); malva (eigenlijk de wetenschappelijke naam van een geslacht waarmee in het $A B N$ een aantal vertegenwoordigers daarvan worden aangeduid): Lippia alba (Verbenaceae); denneboom: een soort Casuarina (Casuarinaceae); sagopalm: Cycas revoluta (Cycadaceae).

Nuttige planten: ceder (S sedre): de boom Cedrela odorata (Meliaceae); amandel(boompje) (S amandra-oedoe): (vrucht 
van) Terminalia catappa (Combretaceae); appel (S apra) : (vrucht van) Syzygium samarangense (Myrtaceae); kers(eboom) (S kersi): (vrucht van) Eugenia uniflora (Myrtaceae); pruim: (vrucht van) Chrysobalanus icaco (Chrysobalanaceae); sterappel: (vrucht van) Chrysophyllum cainito (Sapotaceae); laurierkers: (vrucht van) Chrysophyllum cuneifolium (Sapotaceae); olijf: (vrucht van) Zizyphus jujuba (Rhamnaceae); kalebas (S krabasi): vrucht van de kalebasboom (Crescentia cujete, Bignoniaceae); mispel (S mesper): bijna alle soorten van de familie Melastomataceae en hun vruchten; oker (S okro): (vrucht van) Hibiscus esculentus (Malvaceae), een groente; kapucijner: cultuurvorm van Vigna sinensis (Papilionaceae); postelein (S posren, Talinum triangulare, Portulacaceae) én spinazie (Basella alba, Basellaceae) smaken beide ongeveer als postelein.

Hippeastrum puniceum en enige soorten Crinum (Amaryllidaceae) worden lelie genoemd. Waterlelie is Crinum erubescens. Met een voorvoegsel komen nog enige andere lelies voor onder de sierplanten: eier-, jozef-, vlies- en klimmende lelie (Amaryllidaceae), Braziliaanse en gemberlelie (Zingiberaceae), zwaardlelie (Iridaceae).

Overige soorten: brandnetel is Jatropha urens (Euphorbiaceae), een struikje met gemene stekels, en duivelsnaaigaren is Quamoclit pennata (Convolvulaceae).

SURINAAMS NEDERLANDSE NAMEN VOOR ORGANISMEN DIE IN HET ABN ANDERS HETEN

Dieren

Witlip is pekari en witdas halsband-pekari; het zijn beide ouderwetse woorden. Nog volop in gebruik zijn lepelbek voor (roze) lepelaar, tapijtslang voor boa en draagmier voor parasol- of bladsnijdermier.

\section{Planten}

De volgende drie woorden zijn alle ouderwets: duizendbeenboom voor mangrove (enige soorten Rhizophora), gideonsappel voor pompelmoes en man-van-woord voor broodvruchtboom 
(niet de vorm die kastanjeboom wordt genoemd).

De naam Spaans spek (S panspeki) komt in het ABN niet meer voor sedert de Nederlander de hiermee eertijds aangeduide nietveredelde vorm van de meloen niet meer kent. In Suriname kent men de vrucht en de naam nog wel.

Arabische koffie (Coffea arabica) heet in het SN Surinaamse $k o f f i e$, ter onderscheiding van de gewone koffie (Coffea liberica).

Het oud-Nederlandse woord oranjeboom wordt nog wel gehoord voor de gewone sinaasappelboom. Oranje komt ook verder alleen voor in samenstellingen: Curaçaose oranje voor een type mandarijn, zoete en zure oranje voor twee vormen van de sinaasappel.

Tenslotte: boomananassen zijn de grote soorten Bromeliaceae die in het wild op bomen groeien.

WOORDEN DIE IN HET ABN IETS GEHEEL ANDERS BETEKENEN

\section{Dieren}

Drie zangvogels: dansmeestertje (Volatina jacarina ssp. splendens), grafrust (ouderwets, Mimus gilvus) en grenadier (Euphonia kajana).

Verder: chinees (S snési, mensevlo), scharenslïper (zingcicade) en zoutje (kleine soort kwal).

\section{Planten}

Pompon (een type mandarijn), en de sierplanten biefstuk (kerstster), meisjeslippen (christusdoorn), bokkepoot (Alpinia purpurata, Zingiberaceae) en standvastig (S stanfasti, Gomphrena globosa, Amaranthaceae).

Dieren

REST

De naam voor de rode brulaap is, evenals in het Sranan, baboen. In het Engels, waaruit dit woord afkomstig is, betekent baboon 
echter baviaan. De naam hoort dus thuis bij buffel, tijger, haas e.d.

Hindostaanse boeren in Suriname en in navolging van hen ook de Creolen van Nickerie, spreken van bull (E) wanneer ze stier bedoelen, wat wel zal samenhangen met het feit dat dit dier in het Hindi bail heet (Staffeleu 1975).

Een ouderwets woord voor ezel is chamar, afkomstig uit het Hebreeuws. Ik vond ook de schrijfwijze gammor.

Ik ben er niet achter gekomen waarvandaan de vogelnamen galin (grote zilverreiger) en gonini (harpij of apenarend) komen. De klank doet vermoeden dat het Indiaanse woorden zijn.

Een mug wordt algemeen muskiet genoemd, een woord afkomstig van het Spaans-Portugese en in het Engels onveranderd overgenomen mosquito; het Sranan woord is maskita.

\section{Planten}

Een banaan (S bana) is in Suriname een banaan die niet rauw gegeten kan worden maar eerst moet worden gekookt, gebakken of geroosterd. Een banaan geschikt voor onmiddellijke consumptie heet bakove (S bakba). Er bestaat ook een bananebakove! De banaan is afkomstig uit ZO-Azië en bereikte Amerika via Afrika. De woorden banaan en bakove zijn beide van Afrikaanse oorsprong, maar de literatuur is niet duidelijk over de details. Opmerkelijk is een citaat in Simons (1958) van Otto Keye (1659): 'De Banantas sijn de Baccones, (), doch vallen die selve langer en drooger noch en sijn niet so milt van smaeck.'

De naam roodborstje wordt niet alleen gegeven aan de al genoemde vogel, maar ook aan een vrucht, nl. een type mango met een opvallend rode kleur aan één kant.

Advokaat ( $\mathrm{S}$ afkati) is de naam voor Persea americana (Lauraceae) en de vrucht daarvan, die in Nederland (en in het Engels) genoemd wordt bij de Spaanse naam avocado.

Een moeilijk geval is de boulanger, een wat kortere vorm van de aubergine. Deze naam, ook in gebruik op de Bovenwindse Eilanden, zal wel niets te maken hebben met het Franse woord voor bakker, hetgeen het in feite betekent. Wel lijkt het op het eertijds in Suriname gebruikelijke béranger of bérangère, dat aansluit bij de Franse volksnaam béringène, het Spaanse berenjena en het Curaçaose berehein of barrehein. 
Het varentje venushaar heet in het $\mathrm{SN}$ maidenhair (E), en vroeger hoorde men voor mangrove (Rhizophora) de vertaling van het Engelse oister-tree: oesterboom. Spier voor maiskolf is vermoedelijk een vernederlandsing van het Engelse spire, dat aar betekent, terwijl ook koren voor mais (S karoe) overeenkomt met één van de betekenissen van het Engelse corn.

Papajagras (S papajagrasi) is de kleine lisdodde, waarvan door de Javanen in Suriname ligmatten gevlochten worden. Javaans papaja, overgenomen in het Sranan, betekent ligmat.

De recent ingevoerde Pinus caribaea, een den, wordt door iedereen pinus genoemd, waardoor de naam denneboom gereserveerd blijft voor de al veel langer aanwezige Casuarina.

Het Maleise padi is in Azië geoogste rijst nog in de halm of althans ongedorst. In Suriname is het geoogste en gedorste, maar nog niet gepelde rijst.

\section{LITER A TUUR}

Ahlbrinck C.ss.R., W., 1931. Encyclopaedie der Karä̈ben. Verhand. Kon. Ned. Akad. Wetensch. Amsterdam, afd. Letterk. N.S. 27 (1), 556 pp.

Benjamins, H.D. \& Snelleman, J.F. (red.), 1914-1917. Encyclopaedie van Nederlandsch West-Indië. 's-Gravenhage/Leiden.

Bruggencate, K. ten, 1962. Engels woordenboek - Engels-Nederlands. 16e druk. Groningen.

Dale, van, 1970. Groot woordenboek der Nederlandse taal. 2 delen. 9e druk. 's-Gravenhage.

Echteld, J.J.M., 1961. The English words in Sranan. Diss. Universiteit van Amsterdam. Groningen.

Haverschmidt, F., 1958. Birds of Surinam. Londen/Edinburgh. 
Onions, C.T. (red.), 1967. The shorter English dictionary on historical principles. 3e druk, herdruk 1967. Oxford.

Ostendorf, F.W., 1962. Nuttige planten en sierplanten in Suriname. Bull. Landbouwproefstation Suriname 79, 325 pp.

Simons, R.D., 1958. Bananen en bacoven. Djogo 1 (2), p. 2 -4.

Staffeleu, P., 1975. Surinaamse zoogdiernamen. Zool. Bïdragen RMNH Leiden $18,74 \mathrm{pp}$.

Vermeulen, Frater J., 1961. Dierkunde voor Suriname. Se druk. Paramaribo.

Woordenboek der Nederlandse taal. 's-Gravenhage/Leiden.

Woordenlijst van de Nederlandse taal, 1954. 's-Gravenhage.

Woordenlijst van het Sranan-tongo, 1961. Paramaribo.

Schrijver is dank verschuldigd aan de heer G.W. Noldus voor het krities doornemen van de tekst.

Dr. J. van Donselaar

Hasebroeklaan 1, Bilthoven. 